\title{
GEOPROCESSAMENTO DE DADOS GEOLÓGICOS PARA MAPEAMENTO DE FAVORABILIDADE PARA COBRE, CHUMBO E ZINCO NO VALE DO RIBEIRA (SP-PR)
}

\author{
CARLOS CÉSAR DE ARAÚJO \& ARLEI BENEDITO MACEDO
}

\begin{abstract}
GIS APPLICATION OF GEOLOGICAL DATA FOR FAVORIBILITY MAPPING FOR COPPER, LEAD AND ZINC IN RIBEIRA VALLEY (SP-PR) The paper describes geological data analysis for favorability evaluation of a base-metal mineralized area. The target area comprises Cerro Azul and Apiaí quadrangles (SG.22-X-B-IV and V, scale 1:100,000), Vale do Ribeira, São Paulo and Paraná States. The employed method is based on review of genetic and descriptive models developed on the area and definition of prospective models, application of prospective parameters according to GIS techniques, aiming the generation of favorability maps. to digital datasets, composed of geological, geochemical, airborne geophysics and mineral occurrences. The description, selection and analysis of exploration parameters were based on two mineralization models: Panelas type, vein-type carbonate hosted, and Perau type, sedimentary-exhalative. The prospective parameters applied were considered suitable for the Perau and Panelas favorability maps. For the Perau model, the most favorable areas are related to stratigraphic and lithological factors specially the quartzite-schist contacts. For the Panelas model, the schist-carbonate contacts comprise the most favorable areas. It is concluded that the method used is suitable for selection, keeping low cost, of areas for detailed geological survey and can be applied to similar areas as the studied one.
\end{abstract}

Keywords: Lead, favorability, GIS, Ribeira Valley

Resumo Neste trabalho é descrita a análise de dados geológicos visando a avaliação da favorabilidade de mineralizações de metais básicos, na área das folhas Cerro Azul e Apiaí (SG.22-X-B-IV e SG.22-X-B-V), escala 1:100.000, Vale do Ribeira (SP e PR). O método utilizado baseia-se no estudo dos modelos genéticos e descritivos desenvolvidos na área. definição de modelos prospectivos, escolha dos parâmetros prospectivos e aplicação destes segundo técnicas de geoprocessamento em um conjunto de dados espaciais digitais, composto por dados geológicos, geoquímicos, aerogeofísicos e de ocorrências minerais. A descrição dos modelos de mineralização, a seleção dos parâmetros prospectivos e as análises para geração de mapas de favorabilidade foram feitas com base em dois modelos genéticos: o tipo Panelas, filonar hidrotermal encaixado em rochas carbonáticas, e o tipo Perau, sedimentar-exalativo. A partir dos mapas de favorabilidade definiu-se que os parâmetros prospectivos adotados mostraram-se adequados qualitativamente e quantitativamente, tanto para o tipo Perau quanto para o tipo Panelas. Para o modelo Perau, as áreas mais favoráveis estão relacionadas aos fatores litológicos e estratigráficos especialmente aos contatos xistos-quartzitos. Para o modelo Panelas, os contatos xistos-carbonatos compreendem as áreas de maior favorabilidade. Conclui-se que o método utilizado é adequado à seleção, a baixo custo, de áreas para pesquisa geológica de detalhe, podendo ser aplicado em áreas semelhantes à estudada.

Palavras-chave: chumbo, favorabilidade, SIG, Vale do Ribeira.

INTRODUÇÃO A definição de favorabilidade mineral utilizando sistemas de informação geográfica (SIG) requer um trabalho sistemático de composição de bancos de dados espaciais e de seus atributos. A composição adequada destes bancos de dados é etapa fundamental para uma boa qualidade dos resultados obtidos. O processo de seleção dos dados, baseado nos modelos genéticos e prospectivos desenvolvidos para a área de estudo, auxilia na definição de quais tipos de dados poderão ser utilizados na análise de favorabilidade.

Segundo Bonham-Carter (1994), na aplicação de um SIG no mapeamento de potencial mineral, o modelo de depósito é importante, tanto na seleção quanto na derivação (separação de classes de interesse) de mapas que representariam os melhores metalotectos do modelo em questão. Além disso, os modelos podem auxiliar na definição dos pesos de cada mapa segundo sua importância.

O Vale do Ribeira foi escolhido como área-teste devido ao seu potencial mineral para minérios metálicos, especialmente sulfetos de metais como chumbo, zinco e cobre, dos quais conhecem-se numerosas mineralizações. A organização destes dados é fator importante no processo de avaliação da favorabilidade para mineralizações de chumbo, zinco e cobre na região e o êxito do trabalho é fortemente condicionado pelos modelos de mineralização empregados para a manipulação e interpretação dos dados levantados em campo.

Neste trabalho foi desenvolvida a análise de favorabilidade mineral para metais básicos numa área do Vale do Ribeira, utilizandose técnicas de geoprocessamento, visando a priorização de alvos para prospecção. Foram revistos e tabulados os modelos genéticos, descritivos e prospectivos para metais básicos definidos para as mineralizações da área. A partir desta revisão, buscou-se organizar as informações disponíveis em um SIG e separar os elementos presentes nos modelos que podem ser utilizados numa análise por geoprocessamento. Estes elementos utilizados para a análise de favorabilidade são denominados fatores. Também foram utilizados dados geoquímicos de sedimentos de corrente e dados aeromagnéticos, que foram integrados e analisados em um SIG. Neste caso o termo SIG é utilizado, segundo Bonham-Carter (1994), para definir um sistema computadorizado de manipulação de dados 
espaciais. Esta definição enfatiza SIG segundo os programas e sistemas utilizados. Já o termo geoprocessamento é empregado, segundo Rodrigues (1990), para definir o conjunto de tecnologias de coleta e tratamento de informações espaciais e de desenvolvimento, e uso de sistemas que as utilizam.

O método utilizado baseia-se no desenvolvimento de modelos de prospecção e sua aplicação segundo técnicas de geoprocessamento a conjuntos de dados digitais geológicos, geoquímicos, geofísicos e de ocorrências minerais, digitalizados e espacialmente registrados (Bonham-Carter et al. 1988). O método tem como base a ponderação de fatores, segundo sua importância relativa e absoluta atribuída por peritos (Harris 1984, Harris 1990, Bonham-Carter 1994). A escolha de um método baseado na ponderação subjetiva definida por peritos (knowledge driven) é justificada com o objetivo de utilizar a opinião de especialistas que podem tomar decisões acertadas com base em um pequeno conjunto de evidências e também em áreas de conhecimento geológico restrito. Os métodos baseados nos dados (data driven) não podem ser utilizados em áreas onde estes são insuficientes para a aplicação de técnicas estatísticas de derivação de modelos e ponderação. Embora o Vale do Ribeira seja uma área com um razoável conjunto de dados geológicos, geoquímicos, geofísicos e de ocorrências minerais, sua distribuição espacial, escalas de levantamento e, por vezes, localização são de qualidade irregular. Os dados de ocorrências minerais apresentam problemas de localização, duplicidade com diferentes nomes e descrição geológica. Desse modo obteve-se, após conferência das ocorrências, um conjunto menor de dados que contém aproximadamente $23 \%$ do conjunto original. O número de ocorrências é um fator limitante à aplicação do método baseado nos dados. O método baseado na ponderação subjetiva é mais adequado neste caso especialmente para se utilizar as ocorrências disponíveis exclusivamente para se conferir os mapas de favorabilidade resultantes do processo de análise.

LOCALIZAÇÃOECARACTERÍSTICASGEOLÓGICASDA ÁREA DE ESTUDO A área de interesse para este trabalho localiza-se no sul do estado de São Paulo e nordeste do estado do Paraná, compreendendo a parte superior da bacia do Rio Ribeira de Iguape e áreas adjacentes (Fig. 1). A área estudada abrange aproximadamente $5.800 \mathrm{~km}^{2}$ das folhas Cerro Azul e Apiaí, escala 1:100.000 (SG-22-X-B-IV e SG-22-X-B-V). A área é delimitada pelos

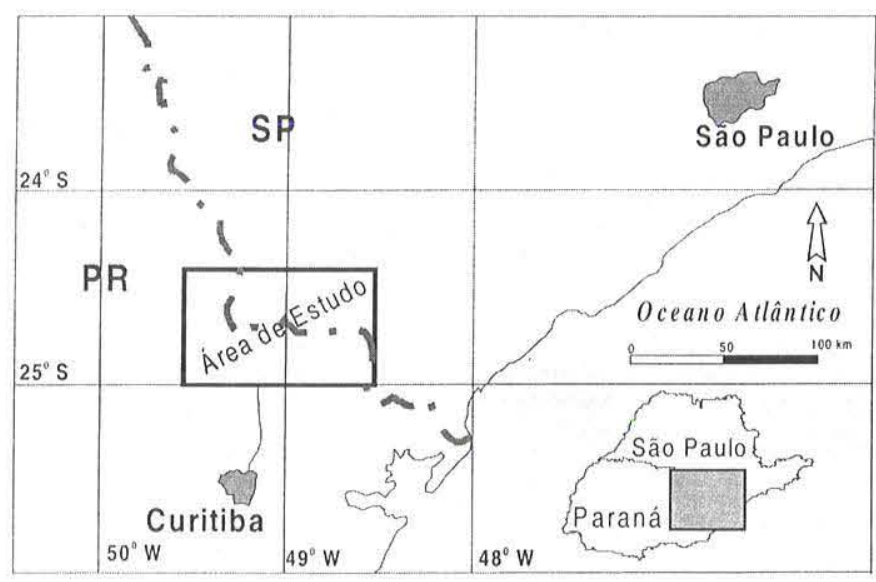

Figura 1- Localização da área de estudo.

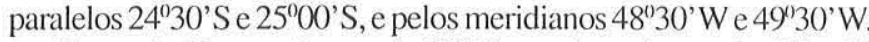

Segundo Campanha et al. (1996), na área de estudo (Fig. 2) predominam rochas supracrustais de grau metamórfico fraco a médio, reunidas no Supergrupo Açungui (Mesoproterozóico a Neoproterozóico). Este é subdividido nos Grupos Itaiacoca, Votuverava (Subgrupos Ribeira e Lajeado), Setuva e Formações Água Clara e Capiru. O embasamento dessas supracrustais, representado pelo complexo Gnáissico Migmatítico (Paleoproterozóico), é constituído por rochas gnáissicomigmatíticas, com núcleos charnockíticos e intercalações de metassedimentos. Granitos do Neoproterozóico, corpos alcalinos do Cretáceo e diques básicos do Mesozóico cortam as seqüências metassedimentares e seu embasamento. Acompanhando os principais rios ocorrem depósitos quaternários aluvionares e coluvionares.

OBJETIVOS E MÉTODOS O método de trabalho empregado (Fig. 3) envolve três etapas básicas discriminadas como preparação, tratamento de dados e integração. Estas três etapas caracterizamse pelo intercâmbio de atividades entre elas, ou seja, durante a etapa de preparação é preciso considerar as necessidades das etapas de tratamento de dados e integração. Mesmo durante as etapas finais de integração há necessidade de se considerar os conceitos definidos nas etapas de preparação e tratamento e mesmo retomar atividades em princípio concluídas.

A etapa de preparação envolve atividades relativas à modelagem dos dados e à construção dos conjuntos de dados digitais. A modelagem envolve o estudo dos modelos genéticos

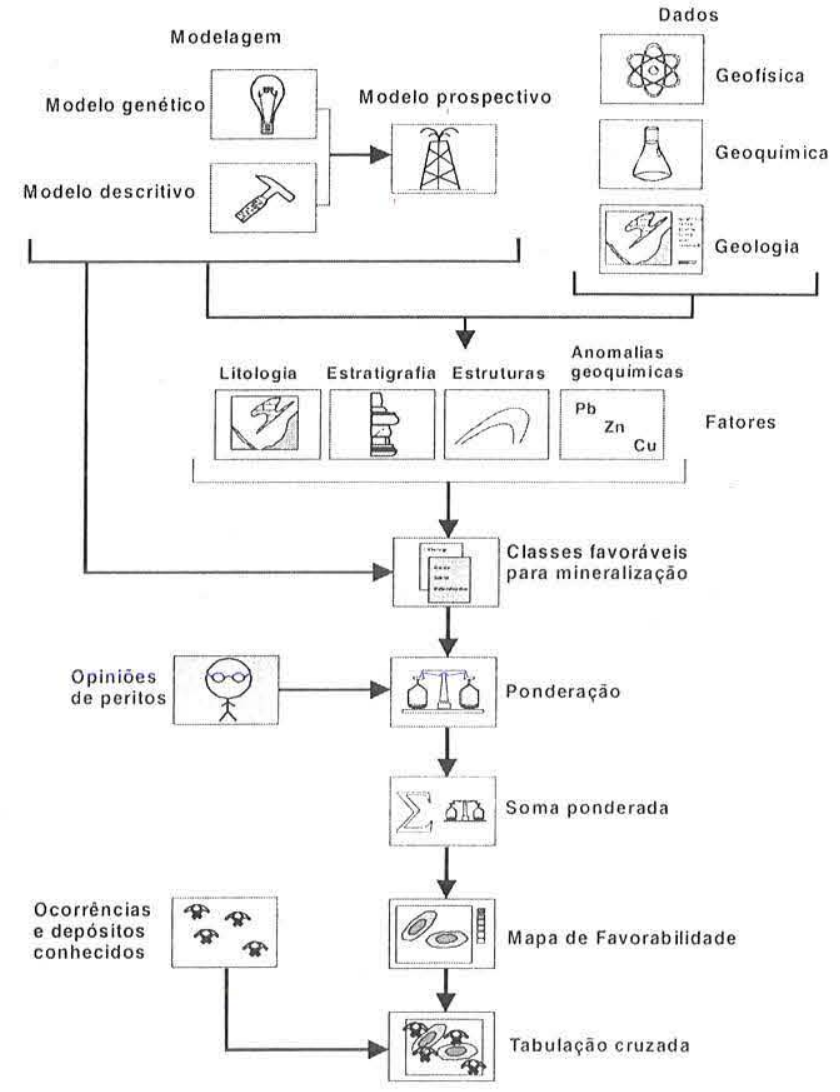

Figura 3 - Fluxograma com as etapas de análise de favorabilidade. 


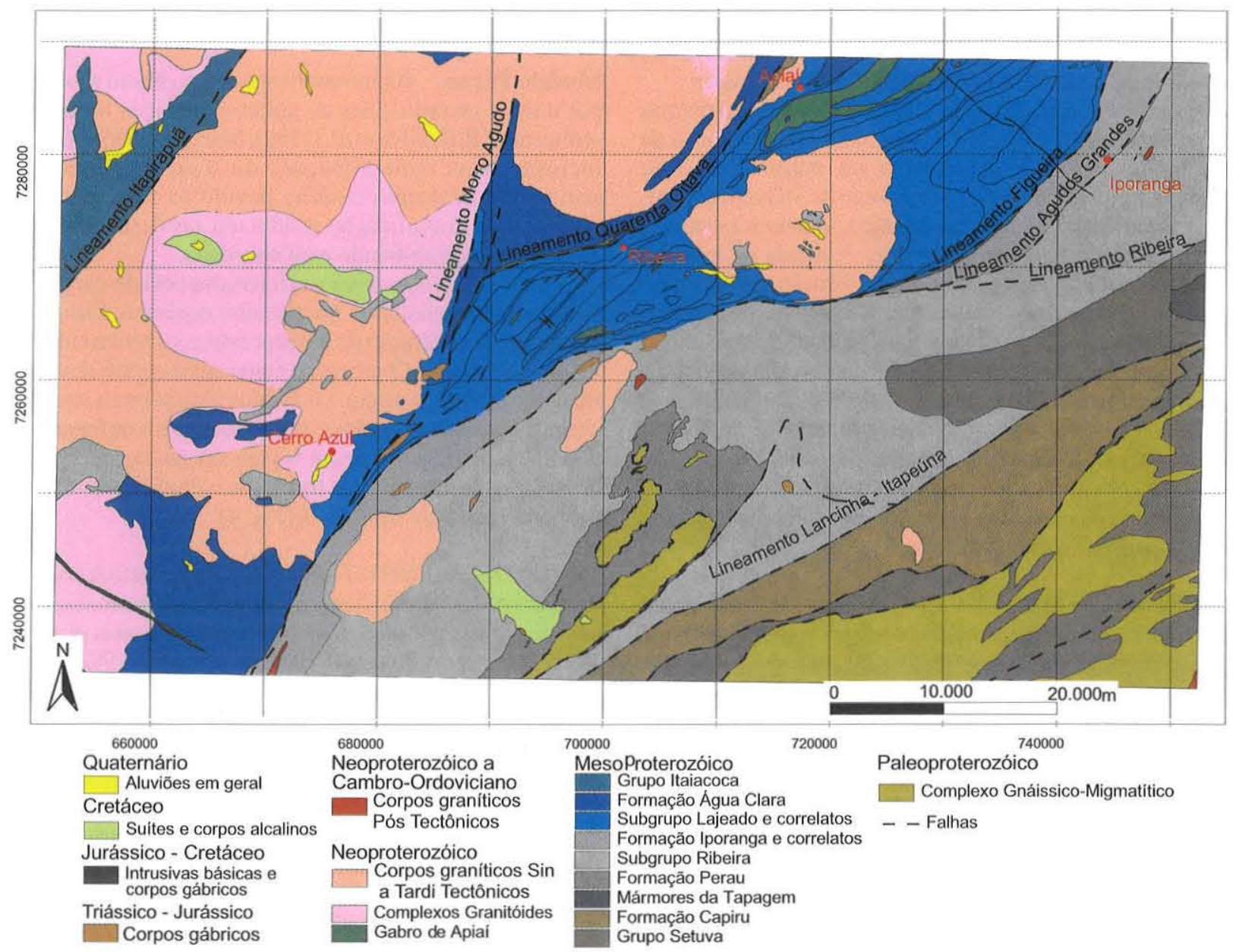

\section{Figura 2 - Esboço litoestratigráfico da área de estudo.}

conhecidos para os bens minerais envolvidos, a separação dos elementos pertencentes ao modelo descritivo e finalmente a construção de um modelo descritivo ajustado aos dados disponíveis. Durante esta etapa procede-se à digitalização dos dados e à conversão de formatos para composição de conjuntos de dados digitais integrados. Os produtos desta etapa são os modelos prospectivos e os conjuntos de dados digitais formatados. Em síntese, o método empregado para modelagem é baseado em quatro fases: estudo dos modelos genéticos, estudo dos modelos descritivos, definição dos modelos prospectivos e separação dos parâmetros prospectivos aplicados por geoprocessamento. Estas quatro fases não são desenvolvidas de modo estanque; durante o desenvolvimento de cada fase definem-se as características das fases posteriores e buscam-se informações das fases anteriores. O ponto chave do método empregado está relacionado à definição do modelo prospectivo e, a partir deste, à definição dos parâmetros aplicados por geoprocessamento.

A etapa de tratamento de dados lida com as informações em formato digital e com os conceitos previamente definidos para o modelo descritivo. Esta etapa caracteriza-se pela aplicação dos conceitos aos conjuntos de dados digitais. O produto desta etapa está na forma de mapas digitais com as informações relevantes para o mapeamento de favorabilidade.

A etapa de integração de dados diz respeito aos métodos empregados na avaliação de favorabilidade, sejam os conduzidos pelo conhecimento (knowledge-driven) ou conduzidos pelos dados (data-driven models).

Este trabalho teve por objetivo principal a discussão do método de tratamento dos dados para a separação dos elementos de interesse. Deste modo, há ênfase nas etapas de preparação e tratamento de dados geológicos. Também foram empregados dados geoquímicos e aerogeofísicos, complementarmente. O método empregado para a determinação de favorabilidade, ou seja, integração de dados, foi o método conduzido pelo conhecimento. Este método assim como a ponderação subjetiva são detalhadamente discutidos por Araújo \& Macedo (2002).

A busca de um método de avaliação de favorabilidade baseado principalmente no contexto geológico das mineralizações conhecidas conduz à necessidade de um conhecimento profundo de suas características geológicas. Deste modo, justifica-se a escolha da área de estudo em uma região que historicamente foi alvo de pesquisas e onde há um grande número de publicações descrevendo diversos aspectos geológicos das ocorrências. Optou-se primeiramente pelo estudo dos modelos genéticos baseado nos dados bibliográficos e, em seguida, foram separadas as características descritivas de cada modelo genético descrito, obtendo-se os modelos descritivos. A partir dos modelos genéticos e características dos modelos descritivos, foram separados os elementos que poderiam contribuir para o rastreamento das mineralizações, ou seja, os parâmetros 
prospectivos. Deste modo foi definido o modelo prospectivo. A partir da separação daqueles parâmetros prospectivos aplicáveis em uma análise de favorabilidade foram definidos os fatores.

Não é possível utilizar todos os parâmetros definidos para os modelos prospectivos devido às peculiaridades da utilização de sistemas de informação geográfica no mapeamento de favorabilidade. Entre as limitações ao emprego de SIGs encontramse as relacionadas tanto à escala de trabalho, quanto à existência e disponibilidade dos dados/informações. A escala de trabalho deve ser adotada durante as etapas de construção do banco de dados e deve considerar a escala dos mapas e projetos disponíveis e o nível de detalhe dos modelos geológicos empregados. A limitação imposta pela disponibilidade dos dados/informações diz respeito à incompatibilidade entre os modelos empregados e os dados disponíveis. Por exemplo, determinadas associações mineralógicas, importantes no rastreamento de mineralizações, não são utilizadas devido à falta de mapeamento sistemático deste tipo de dado, assim como ocorre com controles estruturais que também não foram mapeados sistematicamente.

MODELOS DESCRITIVOSE GENÉTICOS SegundoLydon (1990), um modelo de depósito mineral pode ser composto por: um modelo descritivo, o qual trata de feições do conjunto geológico, tais como morfologia, quimismo, mineralogia, zoneamento e por um modelo genético, no qual são apresentadas explicações das características do tipo de depósito em termos de conhecimento dos processos geológicos.

O conhecimento de mineralizações de uma determinada área é, em geral, organizado a partir das descrições das características geológicas das ocorrências minerais de interesse, tais como mineralogia, estrutura, distribuição espacial e estratigrafia. Esta etapa é exclusivamente derivada de observações, ou seja, é fatual e objetiva; o produto desta etapa é chamado modelo descritivo.

A partir dos dados tabulados pode-se considerar a presença de mais de um tipo de mineralização. Com o agrupamento de características geológicas e sua distribuição espacial, pode-se incluir, por dedução, outros fatores indicativos da gênese das mineralizações estudadas. Esta etapa de classificação é derivada tanto das observações quanto de deduções lógicas. O produto deste trabalho de classificação e dedução pode ser chamado de modelo genético. A partir das características descritivas e das idéias contidas nos modelos genéticos procura-se separar os elementos que podem auxiliar no rastreamento de mineralizações. Estes elementos irão compor o modelo prospectivo.

A sequiência lógica, modelo descritivo-genético-prospectivo, não foi obedecida estritamente no método aqui empregado. Devido ao conhecimento prévio, baseado em grande número de publicações, optou-se pela seguinte ordem de trabalho: primeiramente foi feita a revisão bibliográfica e foram definidos os principais modelos genéticos para a área; estes modelos genéticos foram revistos e a partir deles foram apresentadas as características dos modelos descritivos. Esta fase culminou com a separação das ocorrências minerais conhecidas na área; finalmente, com base na revisão bibliográfica e descrição de ocorrências, foi definido o modelo descritivo e foram separados os parâmetros prospectivos.

As principais mineralizações de sulfetos de metais básicos na área de estudo podem ser agrupadas em dois tipos principais: tipo Perau e tipo Panelas (Fleischer 1976). O tipo Perau compreende mineralizações estratiformes de origem sedimentar-exalativa hospedadas em sedimentos carbonáticos marinhos. O tipo Panelas compreende mineralizações filonares de origem hidrotermal hospedadas em rochas carbonáticas marinhas.

Modelo Perau As mineralizações tipo Perau são compostas por corpos estratiformes de sulfetos maciços hospedados em sedimentos. R.B. Silva et al. (1982), Macedo (1986) e Daitx (1996) incluem estas mineralizações do Vale do Ribeira no tipo sedimentar exalativo (sedex) devido às suas características locais. Esta classificação é adotada no desenvolvimento da análise de favorabilidade aqui abordada.

Os depósitos tipo sedex são formados pela descarga de fluidos hidrotermais metalíferos no assoalho oceânico. Esta descarga é propiciada pela geração de um processo convectivo em um grande volume de fluido. O processo convectivo ocorre devido ao alto fluxo térmico na litosfera. Os fluidos hidrotermais mineralizados chegam ao assoalho oceânico por meio de áreas de fraqueza crustal, que funcionam como condutos para sua passagem. Pode ocorrer deposição de metais, na forma de vênulas, nestes condutos formando zonas de stockwork (Fig. 4).

MODELODESCRITIVO-PERAU Para a definição do modelo descritivo das mineralizações tipo Perau foram consideradas características apontadas na bibliografia (Souza \& Campanha 1977, Barbour \& Oliveira 1979, R.B. Silva et al. 1982, C.R. Silva et al. 1982, Macedo 1986, Daitx 1996), com ênfase nos fatores condicionantes da mineralização, observados nas minas e ocorrências da área, principalmente os considerados de importância genética. Os elementos que compoem este modelo são apresentados a seguir:

- estratigraficamente, as ocorrências minerais estão associadas à Formação Perau, mais especificamente à sequiência carbonática/pelítico-carbonática (Daitx 1996). O contato entre os quartzitos e os pelitos da Formação Perau é um guia prospectivo importante. Além disso, é possível estender o fator estratigráfico a níveis correlacionáveis à Formação Perau, presentes na região, como o Subgrupo Ribeira (Campanha et al. 1996);

- litologicamente são consideradas mais favoráveis às mineralizações as rochas carbonáticas, como carbonato xistos com intercalações de mármores e também os dolomitos, e as litologias compostas pela altemância de mármores dolomíticos e mica xistos. Xistos, filitos e rochas metabásicas também são consideradas,

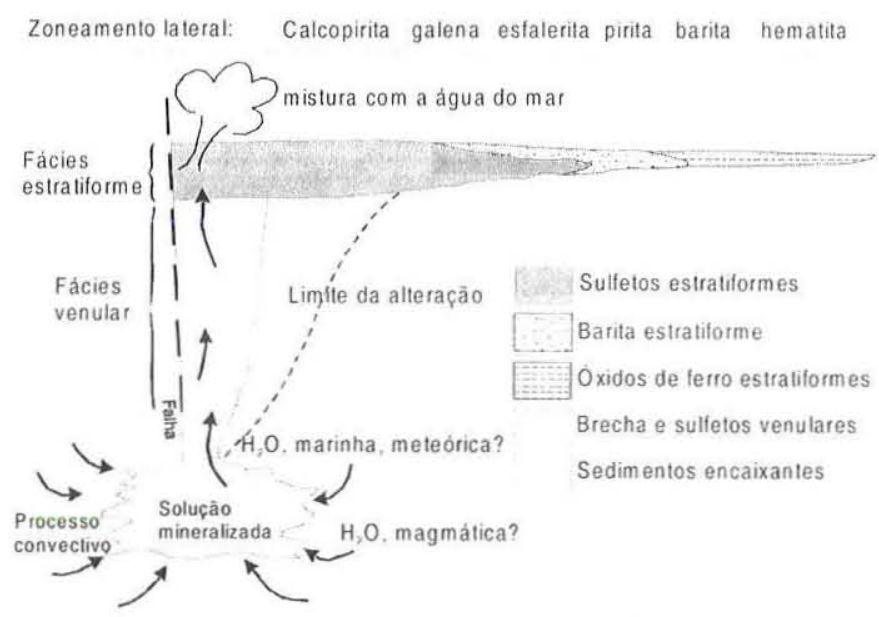

Figura 4 - Mineralização submarina exalativa, hipotética, de sulfetos e barita hospedados em sedimentos. Modificado de Large (1960) e Finlow-Bates (1980). 
mas com menor importância. As rochas metabásicas são utilizadas como indicação das fontes de calor no processo hidrotermal; os xistos e filitos podem caracterizar o ambiente basinal;

- um guia prospectivo importante deste tipo de mineralização são as formações ferríferas bandadas e níveis baritíferos que, em geral, capeiam o nível mineralizado estratiforme;

- é preferível a prospecção visando depósitos integrados de chumbo, zinco e cobre pois a ocorrência simultânea destes elementos é uma característica intrínseca do modelo empregado, além da possibilidade de viabilidade econômica ser maior. Os dados geoquímicos de sedimentos de corrente, onde as anomalias de chumbo, zinco e cobre se referem a uma mesma bacia, são relativamente mais importantes que anomalias isoladas.

- embora o controle estrutural não seja preponderante neste tipo de mineralização, os principais depósitos situam-se nas proximidades de grandes falhamentos, como o Ribeirão Grande (Daitx 1996), e estão alinhados numa direção NE-SW. As características das rochas encaixantes indicam possivelmente um ambiente de bacias de origem tectônica controladas por falhamentos. Em termos de controle estrutural, relacionado à tectônica formadora da bacia, considera-se a possibilidade, embora remota, de uma zona de stockwork, a qual poderia ter se instalado em área de fraqueza crustal, fraturada. De maneira geral considera-se o controle estrutural, na mineralização tipo Perau, como um fator acessório.

Parâmetros prospectivos para depósitos tipo Perau empregados na análise de favorabilidade por geoprocessamento Na aplicação dos parâmetros prospectivos, definidos para as mineralizações tipo Perau, alguns elementos factuais não puderam ser utilizados, devido à incompatibilidade da escala de estudo utilizada em relação à escala de trabalho necessária para a detecção destes elementos. Como exemplo, pode-se citar a não utilização dos níveis baritíferos e formações ferríferas, que capeiam a mineralização.

São apresentados a seguir os parâmetros utilizados na determinação de áreas favoráveis à mineralização utilizando-se técnicas de geoprocessamento.

Foram considerados quatro fatores principais: fator litológico, fator estratigráfico, fator geoquímico e fator estrutural. Estes fatores agrupam os guias prospectivos definidos nos modelos prospectivos. A descrição de cada fator encontra-se na Tabela 1.

Modelo Panelas As mineralizações tipo Panelas correspondem a depósitos compostos por sulfetos filonares encaixados em rochas carbonáticas (Fig. 5). Não há uma caracterização precisa sobre a origem dos fluidos hidrotermais que geraram estas mineralizações. Elas são consideradas como epigenéticas remobilizadas, depositadas nos carbonatos, a partir de um estoque metálico prévio contido nos sedimentos e carbonatos (Damasceno 1967, Fleischer 1976, Odan et al. 1978, R.B. Silva et al. 1982). Outro aspecto é o da restrição das mineralizações a um determinado nível estratigráfico, definindo as mineralizações tipo Panelas como possivelmente strata-bound em termos regionais (Barbour et al. 1988, 1990).

MODELO DESCRITIVO PANELAS As mineralizações tipo Panelas podem ser descritas segundo as seguintes características: morfologia filonar; associação com rochas carbonáticas e rochas dolomítico-quartzosas; caracteristicamente strata-bound; mineralizações associadas aos sistemas de fraturamento, às zonas de falha, aos contatos tectônicos entre litologias terrígenas e
Tabela 1- Descrição dos fatores do modelo prospectivo Perau.

\begin{tabular}{|c|c|}
\hline Fator & Descriçĩo \\
\hline Litológico & $\begin{array}{l}\text { Carbonato xistos com intercalações de mármores. } \\
\text { Alternância de mármores dolomíticos e micaxistos com } \\
\text { tremolita. Xistos com intercalações de quartzitos; AS/AF - } \\
\text { metarritmitos e metargilitos. Metavulcânicas básicas e } \\
\text { ácidas (fator térmico). }\end{array}$ \\
\hline Estratigráfico & $\begin{array}{l}\text { Formação Perau; Subgrupo Ribeira; Contato quartzitos - } \\
\text { pelitos na Formação Perau }\end{array}$ \\
\hline Geoquímico & Anomalias de $\mathrm{Pb}, \mathrm{Cu}$ e $\mathrm{Zn}$ \\
\hline Estrutural & $\begin{array}{l}\text { Falhas; lineamentos magnéticos; zonas de fraqueza estru- } \\
\text { tural - árcas de máxima isofreqüência de fraturamento; } \\
\text { áreas de falha e fraturamento }\end{array}$ \\
\hline
\end{tabular}

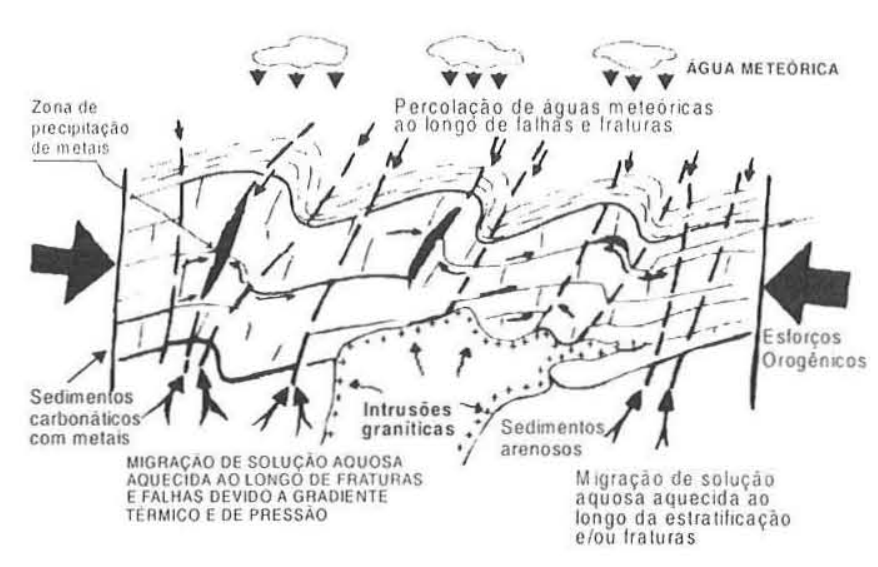

Figura 5 - Modelo genético interpretativo das mineralizações epigenéticas de chumbo do Vale do Ribeira. Modificado de Silva et al. (1982)

carbonáticas e às zonas de charneira de dobras. Do ponto de vista genético, são consideradas epigenéticas, de origem hidrotermal, mesotermal, hospedadas em rochas carbonáticas (Fleischer 1976, Odan et al.1978, Chiodi et al. 1982, Barbour et al.1990, Daitx et al. 1995).

A definição dos parâmetros exploratórios considerou as evidências e hipóteses genéticas levantadas por Damasceno 1967. Fleischer 1976, Odan et al. 1978, Chiodi et al. 1982, R.B. et al. Silva 1982, C.R. Silva et al. 1982, Barbour et al. 1984, 1988 1990, Tassinari et al. 1990, Hasui et al.1992 e Daitx et al. 1995. Os parâmetros de prospecção não foram definidos considerando uma única hipótese genética. Considera-se que várias questões acerca do modelo de mineralização tipo Panelas ainda permanecem sem resposta. A definição dos parâmetros abaixo apresentados considerou tanto os elementos fatuais quanto os elementos lógicos derivados dos modelos genéticos.

- fator litológico, envolvendo rochas carbonáticas como dolomitos e calcários. As rochas dolomíticas configuram-se como componente importante devido à sua maior competência em relação às rochas carbonáticas; esta maior competência originou aberturas, segundo esforços tectônicos, gerando espaços vazios por onde os fluidos mineralizantes percolaram e depositaram seu conteúdo metálico.

- fator estratigráfico compreendendo, principalmente, os níveis carbonáticos do Subgrupo Lajeado. Contudo não se considera este fator como restritivo, mas sim que a esses níveis deve ser atribuído um peso maior, em relação às outras unidades estratigráficas consideradas, como a Formação Itaiacoca e a For- 
mação Água Clara.

- o fator geoquímico envolve anomalias de chumbo, zinco e cobre, defïnidas a partir de levantamentos geoquímicos regionais de sedimento de corrente. As anomalias conjuntas de $\mathrm{Pb}-\mathrm{Zn}-\mathrm{Cu}$ são consideradas mais importantes do que as anomalias de um único elemento;

- o fator estrutural envolve lineamentos, como as falhas, e também os eixos de sinclinais e anticlinais (zonas de charneira). Neste sentido, procura-se utilizar também as zonas de maior freqüência de fraturamento. Considera-se que o fator estrutural tem importância relativa menor do que os outros fatores, devido à escala de trabalho regional. Notou-se que estas mineralizações filonares têm forte controle estrutural; contudo isto é verificado em escala de detalhe e esta característica não pôde ser extrapolada para uma escala regional com o mesmo nível de significância devido à falta de mapeamento estrutural sistemático.

Parâmetros prospectivos para depósitos tipo Panelas empregados na análise de favorabilidade por geoprocessamento $\mathrm{Na}$ definição destes parâmetros prospectivos, consideraram-se também as características da análise feita a partir de sistemas de informação geográfica (SIG). Uma característica relevante é a necessidade de expressão espacial das informações, tanto relacionada à escala de trabalho, quanto à disposição das informações.

Foram considerados quatro fatores, denominados fator litológico, fator estratigráfico, fator geoquímico e fator estrutural, onde estão agrupados os guias prospectivos definidos no modelo prospectivo.

A Tabela 2 contém os elementos de cada fator que serão utilizados a partir dos dados georreferenciados.

DADOS GEOQUÍMICOS Utilizou-se dados geoquímicos de sedimentos de corrente do projeto Geoquímica no Vale do Ribeira (Morgental et al. 1978) cedidos pela Companhia de Pesquisa de Recursos Minerais (CPRM), que incluem os dados do projeto Sudelpa (Morgental et al. 1975), e dados de projetos geoquímicos semi-regionais e de detalhe realizados pela Mineropar na área descritos por Licht \& Tarvainen (1996).

A análise dos dados geoquímicos de sedimentos de corrente é feita observando-se a distribuição de frequiência cumulativa dos dados e modelando-se os parâmetros estatísticos da distribuição de frequiência das populações que compõem o conjunto de dados, permitindo, quando for o caso, separar distribuições mistas em suas componentes normais ou lognormais. Esse modelamento é necessário para a definição da população de valores menores, que representa as dispersões normais de distribuição dos elementos analisados nas bacias (background).

Para separar das populações na área de estudo, seguiu-se a metodologia apresentada por Macedo (1996), que usa o programa

Tabela 2 - Descrição dos fatores do modelo prospectivo Panelas.

\begin{tabular}{|c|c|}
\hline Fator & Descrição \\
\hline Litológico & $\begin{array}{l}\text { Mármores; rochas cálcio-silicáticas, carbonato xistos com } \\
\text { intercalações de mármores: mármores dolomíticos; } \\
\text { alternância de mármores dolomíticos e micaxistos com } \\
\text { tremolita; contato entre rochas carbonáticas e terrígenas. }\end{array}$ \\
\hline Estratigrálico & Subgrupo Lajeado, Grupo Itaiacoca, Formação Água Clara \\
\hline Geoquímico & Anomalia de $\mathrm{Pb} ; \mathrm{Zn} ; \mathrm{Cu}$ \\
\hline Estrutural & $\begin{array}{l}\text { Lineamentos - eixos de dobras, zonas de máxima freqüiência } \\
\text { de fraturamento, falhas, lineamentos magnéticos }\end{array}$ \\
\hline
\end{tabular}

PROBPLOT (Stanley 1987) o qual é uma adaptação computacional da técnica de Williams (1967), que usa gráficos de frequiência acumulada em papel logarítmico. Para todos os arquivos dos projetos foi feita a plotagem dos gráficos de frequiência acumulada. Foram separados os conjuntos de dados onde a curva de frequiência acumulada logarítmica demonstrava ser composta por duas populações distintas, evidenciada por uma forma em S. Utilizou-se a população de menor média aritmética (considerada background), para se calcular sua média geométrica e desvio geométrico. Para os dados nos quais não era possível fazer a separação entre populações componentes, foram calculadas a média geométrica e o desvio geométrico para $100 \%$ das amostras.

O termo limiar (threshold) é utilizado significando um valor específico que distingue conjuntos de dados superiores ou anômalos daqueles conjuntos inferiores ou de background (Sinclair 1974). Dessa forma, os limiares entre background e anomalia foram calculados utilizando-se a equação:

$$
\text { Limiar }={\mathrm{MG} \times \mathrm{DG}^{2}}^{2}
$$

onde $\mathrm{MG}=$ média geométrica e $\mathrm{DG}^{2}$ = desvio geométrico ao quadrado, ambos da população de background.

Um exemplo de gráfico plotado no programa PROBPLOT (Stanley 1987) é apresentado na figura 6, na qual podem ser vistas: a curva de frequiência acumulada com formato em $\mathrm{S}$, as retas das populações componentes e os dados de média e desvio padrão das duas populações.

Com o valor de limiar de anomalia calculado pode-se definir o valor de contraste de anomalia para cada amostra, que é obtido dividindo-se o teor de uma amostra pelo limiar de anomalia, definido para a população de origem da amostra. O valor de contraste é uma medida relativa, um valor sem dimensão. Os valores de contraste são úteis para se comparar valores de bacias anômalas e não anômalas, entre dados originários de diferentes populações e projetos. O procedimento com valores de contraste é especialmente

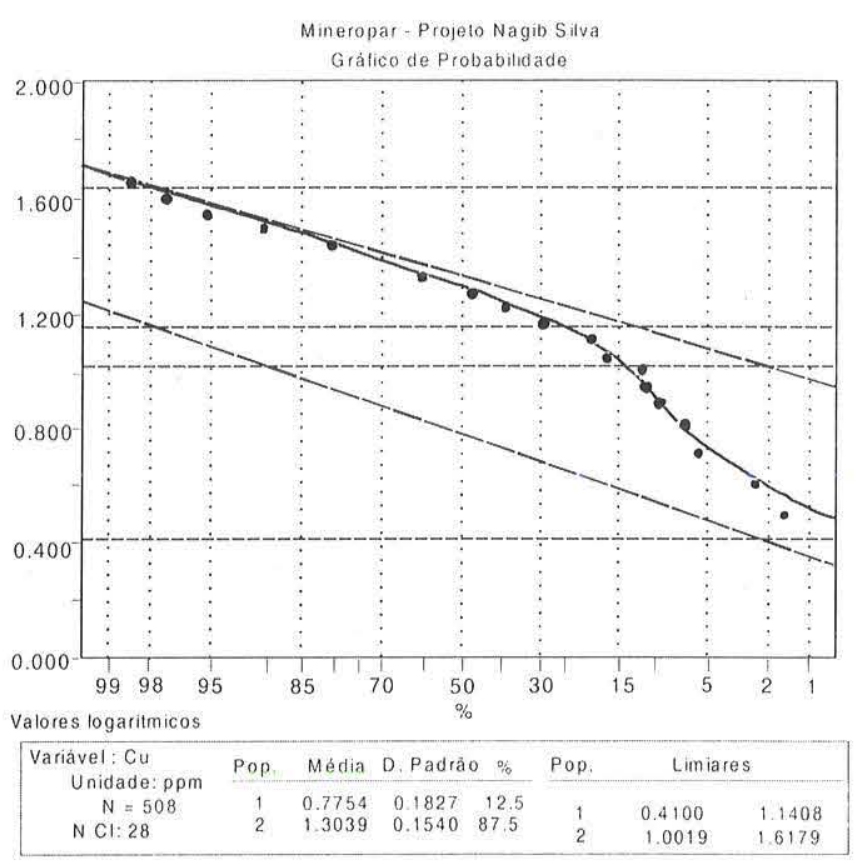

Figura 6 - Exemplo de gráfico do programa Probplot aplicado à população de dados de um levantamento geoquímico (Projeto Nagib Silva). 
útil no caso de compilação de dados de projetos geoquímicos de diferentes origens e não padronizados. Apenas a análise das anomalias poderia conduzir a um desvio nos resultados para um projeto cujos dados têm valores médios de background e anomalia relativamente altos quando comparados a outros projetos. Ao utilizar os valores de contraste, os pontos não anômalos terão valores entre maior que 0 e menor que 1 (adimensional); os pontos anômalos têm valores maiores ou iguais a 1, de modo que os maiores valores de contraste correspondem às anomalias cujos teores são muitas vezes maiores que o background.

A partir do arquivo de pontos com os valores de contraste e do modelo numérico de terreno (MNT) foram traçadas as bacias a montante de cada ponto amostrado. Para se fazer o traçado automático das bacias amostradas partiu-se de um arquivo vetorial de pontos. Este arquivo contém todos os pontos e os respectivos atributos, com teores de $\mathrm{Pb}, \mathrm{Zn}$ e Cu, o limiar calculado para cada conjunto de pontos, os valores de contraste e o nome do arquivo de origem. Além dos pontos utilizou-se um modelo numérico de terreno, calculado como rede triangular irregular (TIN triangulated irregular network), como base topográfica O processo utilizado para traçar as bacias automaticamente está descrito no fluxograma da figura 7 .

Após a conclusão da montagem do banco de dados geoquímicos de sedimentos de corrente, obteve-se um mapa temático com as seguintes informações para cada bacia amostrada: área da bacia, teor em ppm atribuído à bacia amostrada para cobre, chumbo e zinco quando disponível, valor do limiar para os três elementos e valor de contraste para os três elementos.

DADOS GEOFÍSICOS Foram utilizados dados dos levantamentos aerogeofísicos Serra do Mar Sul - SMS (CPRM-Geofoto, 1978) e São Paulo - Rio de Janeiro - SPRJ (CPRM-Encal 1979).

O primeiro passo, no tratamento dos dados magnetométricos, foi o nivelamento dos conjuntos de dados dos projetos Serra do Mar Sul (SMS) e São Paulo - Rio de Janeiro (SPRJ). Na área de estudo, as linhas de vôo têm um recobrimento numa pequena porção na região sul da folha Apiaí, 1:100.000 (SG-22-X-B-V). Este

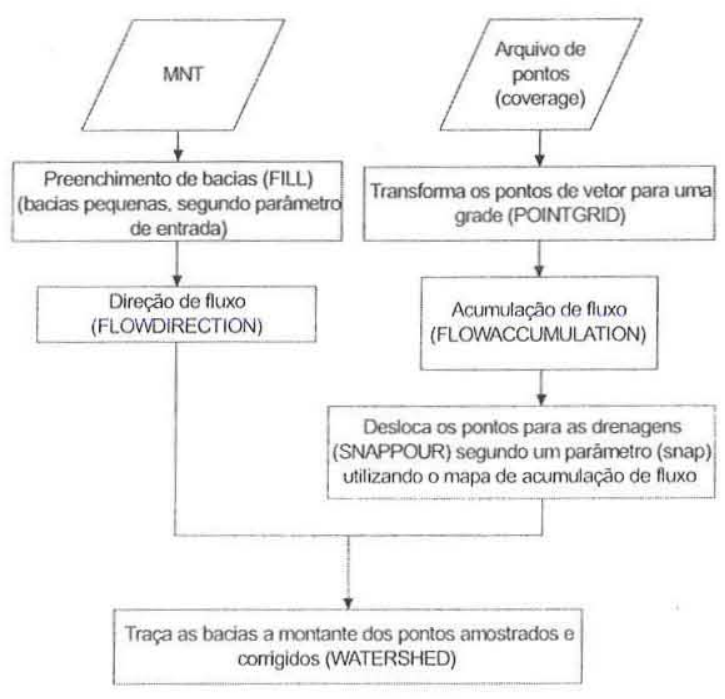

Figura 7 - Fluxograma com as principais etapas para traçar bacias de drenagem automaticamente a partir dos pontos de amostragem de sedimentos de corrente e MNT. recobrimento foi utilizado para definir um valor de correção que seria aplicado a um dos levantamentos. Para isso, foi feita a interpolação dos grids de cada projeto separadamente. Preparouse uma máscara correspondente à área de sobreposição dos projetos e recortou-se a área de recobrimento nos dois gricls. Verificou-se a média dos valores na área de recobrimento em cada grid. Subtraiu-se a média do SPRJ da média do SMS e somou-se esse fator ao grid de menor valor, que neste caso foi a imagem do SMS. Os dois grids interpolados foram submetidos a um filtro de cosseno direcional. Finalmente, foram amostrados a partir do conjunto de pontos original dos projetos SMS e SPRJ; o produto é o de dois conjuntos de dados com informações de filtragem e nivelamento. Estes dois conjuntos foram unidos e procedeu-se a geração da imagem geofísica de campo total utilizando o interpolador de mínima curvatura.

A partir da imagem de campo total com os projetos integrados procedeu-se à geração de imagens de redução ao pólo, de primeira derivada vertical e controle automático de ganho. As anomalias magnéticas em um mapa com redução ao pólo ocorrem verticalmente acima de suas fontes (Gunn et al. 1997) de tal modo que esses mapas são mais simples de se interpretar do que outros onde há inclinação magnética. O controle automático de ganho é uma técnica que cria uma imagem, na qual todas as anomalias são forçadas a ter aproximadamente a mesma amplitude e as anomalias mais fracas são, em princípio, tão evidentes quanto anomalias intensas (Gunn et al. 1997), de modo que tal imagemé muito útil na interpretação de dados estruturais. Gradientes verticais de campos magnéticos representam campos magnéticos nos quais os efeitos regionais e a interferência entre anomalias adjacentes foram suprimidos (Gunn et al. 1997), de tal modo que se pode estudar anomalias locais. Considerando tal processamento numa imagem reduzida ao pólo, teremos a possibilidade de estudar uma anomalia local que se encontra sobre sua fonte, o que pode ser muito útil para a prospecção mineral.

A interpretação dos dados magnetométricos considerou os lineamentos magnéticos, caracterizados por descontinuidades magnéticas eventualmente relacionadas às falhas e eixos de dobras, entre outras possíveis estruturas tectônicas lineares. Os lineamentos magnéticos também foram traçados ao longo de descontinuidades magnéticas marcadas por limites texturais. Da mesma forma, como observado no projeto Anta Gorda (MMAJJICA 1981), não foi verificada uma relação clara entre as mineralizações e as áreas fortemente magnéticas. Conseqüentemente, o pesos das informações interpretadas nos dados aeromagnéticos serão menores em relação a outras informações diretamente relacionadas às mineralizações.

DADOSDE OCORRÊNCIASMINERAIS Obancodedados de ocorrências minerais é baseado nos arquivos digitais do CPRMMicrosiga (1994) e nos arquivos digitais do banco de dados IDEM (Figueiredo 1988). Além disso, foram utilizados dados obtidos a partir da digitalização de ocorrências registradas nos mapas do projeto Anta Gorda (MMAJ-JICA 1981, 1982, 1983). Todos os dados foram organizados na forma de uma planilha eletrônica.

A partir do banco de dados inicial, procurou-se primeiramente eliminar as ocorrências duplicadas. Posteriormente, foi conferida a localização de cada ocorrência baseando-se em trabalhos acadêmicos e projetos de pesquisa mineral em que as ocorrências eram citadas e apresentadas com mapa de localização. Eliminaram-se aquelas cuja localização fosse duvidosa, mantiveram-se apenas os dados consistentes com outros estudos já feitos na região. 
Antes dessa análise crítica, o banco de dados contava com 479 ocorrências, das quais apenas 113 foram mantidas, por serem as informações correspondentes consideradas confiáveis.

Foi feita uma separação das ocorrências considerando dois modelos. tipo Panelas ( 82 mineralizações filonares) e tipo Perau (7 mineralizações estratiformes); para 24 ocorrências os dados eram insuficientes para classificá-las por tipo genético.

\section{DEFINIÇÃO DOS PESOS DOS PARÂMETROS PROSPEC-}

TIVOS A partir dos dados obtidos com os modelos genético, descritivo e prospectivo foram analisados quais elementos, ou seja, os parâmetros prospectivos, poderiam ser efetivamente utilizados na análise de favorabilidade. Os parâmetros prospectivos ponderados e utilizados na análise são chamados de fatores.

Para definir a ordenação dos fatores e a escala de favorabilidade para cada fator, foram atribuídos pesos aos parâmetros prospectivos. A definição destes pesos foi feita a partir de dados bibliográficos e de discussões com geólogos com experiência nessa área de estudo e no tipo de mineralização abordada. Estes profissionais foram considerados peritos. Os peritos, num total de seis, foram consultados a partir de um formulário padronizado cujas respostas obedeciam a um escalonamento de importância variando de 0 a 10. Foram requisitadas justificativas geológicas para as opiniões. Exceto um caso, tanto a entrega quanto o recolhimento dos formulários foram feitos pessoalmente, acompanhados de discussões e anotações.

Os pesos finais apresentados nas Tabelas 3 e 4 a seguir foram definidos pelo primeiro autor, com base nas opiniões tabuladas dos diversos peritos, consideradas tanto do ponto de vista do peso, como número absoluto, quanto das discussões a respeito da justificativa de cada peso.

A análise utilizando ponderadores tem um caráter subjetivo, já que não é possível definir pesos para todas as evidências de um modelo, justificando-as a partir de elementos fatuais.

CONSTRUÇÃO DOS FATORES Na construção dos fatores foram considerados os pesos, atribuídos aos parâmetros prospectivos, numa escala de 0 a 10 , os quais foram reclassificados numa escala contínua de favorabilidade com classes de 0 a 255.

A reclassificação dessas escalas utilizou o método lógico fuzzy. No caso da reclassificação dos fatores, a escala contínua varia de 255 (favorável) a 0 (não favorável).

Na construção dos mapas de fatores foram utilizadas funções lineares e funções sigmoidais. A função sigmoidal foi utilizada para definir a variação de um peso em função de distância, como no caso dos corredores ao redor de estruturas lineares. Neste caso os valores no centro dos corredores (falhas, contatos, eixos de dobras, lineamentos magnéticos) permaneceram proporcionais ao valor original pré-definido e os valores próximos às bordas destes corredores aumentavam ou diminuíam em função do tipo de função adotada (decrescente ou crescente).

A função linear foi utilizada nos casos em que apenas havia necessidade de se reescalonar os valores de uma escala $(0-10$, pesos dos parâmetros prospectivos) para outra $(0$ - 255), especialmente para a reclassificação de níveis de informação mantendose a proporcionalidade dos valores originais. A lógica fuzzy no caso das funções lineares foi empregada apenas para a reclassificação de valores e não para a definição de áreas de incerteza, como foi feito no caso das funções sigmoidais aplicadas aos elementos lineares.

Os valores adotados no pontos de controle das funções
Tabela 3 -Peso dos fatores litológicos, estratigráficos, geoquímicos, estruturais e de suas respectivas classes - modelo Panelas.

\begin{tabular}{|c|c|c|c|c|c|c|c|}
\hline Descriçâo & \multicolumn{7}{|c|}{ Ponderação dos peritos e ponderação final } \\
\hline $\begin{array}{l}\text { Fator litológico } \\
\end{array}$ & 10 & 10 & 10 & 10) & 10) & 9 & 10 \\
\hline $\begin{array}{l}\text { Mármores dolomíticos e } \\
\text { calcíticos - }\end{array}$ & 10 & 10 & I() & 10) & I0 & 10 & 10 \\
\hline $\begin{array}{l}\text { Rochas cálcio-silicáticas, } \\
\text { carbonato xistos com } \\
\text { intercalações de mármores }\end{array}$ & 4 & 4 & 4 & 4 & 6 & 6 & 4 \\
\hline Mármores dolomíticos & 6 & 8 & 8 & 8 & 8 & 6 & 6 \\
\hline $\begin{array}{l}\text { Alternância de mármores } \\
\text { dolomíticos e mica xistos }\end{array}$ & 2 & 4 & 4 & 4 & 6 & 6 & 4 \\
\hline $\begin{array}{l}\text { Fator estratigráfico } \\
\end{array}$ & 8 & 6 & 5 & 8 & 9 & 10) & 8 \\
\hline Subgrupo Lajeado & 10 & I0 & 10 & 8 & 10 & 10 & 10) \\
\hline Grupo Itaiacoca & 6 & 8 & 8 & 6 & 4 & 6 & 8 \\
\hline $\begin{array}{l}\text { Fator geoquímico }\end{array}$ & 6 & 5 & 10 & 6 & 7 & 6 & 7 \\
\hline 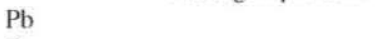 & 8 & 8 & 8 & 6 & 8 & 4 & 10 \\
\hline $\mathrm{Zn}$ & 6 & 6 & 6 & 4 & 6 & 4 & 7 \\
\hline Fator estrutural & 5 & 5 & 5 & 4 & 8 & 6 & 5 \\
\hline Eixos de dobras & 8 & 10 & 10 & 4 & 8 & 10 & 10 \\
\hline $\begin{array}{l}\text { Eixos de máxima frequiência de } \\
\text { fraturamento }\end{array}$ & 6 & 5 & 5 & 8 & 8 & 0 & 5 \\
\hline Falhas & 4 & 5 & 5 & 6 & 10) & 0 & 5 \\
\hline Lineamentos magnéticos & 2 & 2 & 2 & 5 & 6 & 0 & 2 \\
\hline
\end{tabular}

Tabela 4 -Peso dos fatores litológicos, estratigráficos, geoquímicos, estruturais e de suas respectivas classes - modelo Perau.

\begin{tabular}{|c|c|c|c|c|c|c|c|}
\hline Descrição & \multicolumn{7}{|c|}{ Ponderação dos peritos e ponderação final } \\
\hline Fator litológico & 6 & 6 & 10 & 8 & 8 & 7 & 8 \\
\hline $\begin{array}{l}\text { Carbonato xistos com } \\
\text { intercalações de mármores }\end{array}$ & 10 & 10 & 10 & 10 & 10 & 5 & 10 \\
\hline $\begin{array}{l}\text { Alternância de mármores } \\
\text { dolomíticos e mica xistos }\end{array}$ & 6 & 5 & 10 & 8 & 8 & () & 6 \\
\hline $\begin{array}{l}\text { Xistos com intercalações de } \\
\text { quartzitos, metarritmitos e } \\
\text { metargilitos }\end{array}$ & 4 & 3 & 0 & 5 & 6 & () & 3 \\
\hline Fator estratigrálico & 10 & 10 & 5 & 5 & 10 & 10 & 10 \\
\hline Formaçẫo Perau - vp & 8 & 10 & 8 & 7 & 10 & 5 & 8 \\
\hline Subgrupo Ribeira - v & 5 & 5 & 5 & 4 & 6 & 5 & 5 \\
\hline Fator geoquímico & 8 & 8 & 10 & 8 & 6 & 8 & 7 \\
\hline $\mathrm{Pb}$ & 7 & 7 & 7 & 5 & 6 & 6 & 10 \\
\hline $\mathrm{Zn}$ & 6 & 6 & 3 & 3 & 4 & 5 & 5 \\
\hline $\begin{array}{l}\text { Fator estrutural } \\
\end{array}$ & 4 & 4 & 3 & 4 & 5 & 2 & 3 \\
\hline Lineamentos - Falhas & 10 & 7 & 5 & 8 & 8 & 1 & 10 \\
\hline Lineamentos Magnéticos & 4 & 3 & 3 & 5 & 4 & 2 & 2 \\
\hline Zonas de máxima frequiência de & 5 & 5 & 0 & 3 & 6 & 0) & 4 \\
\hline
\end{tabular}

fraturamento

sigmoidais foram discutidos com os peritos, suas opiniões foram tabuladas e os valores finais ponderados pelo primeiro autor. No caso das funções lineares foram observados os valores máximos e mínimos de cada nível de informação. Na construção dos fatores, as classes foram reclassificadas, como descrito nas Tabela 5, segundo os modelos prospectivos adotados.

INTEGRAÇÃODEDADOSESELEÇÃODEÁREASFAVORÁVEIS A integração dos dados para gerar os mapas de favorabilidade foi feita utilizando-se um método de análise multicriterial de dados (Eastman 1997) denominado Análise por Combinação Linear Ponderada (CLP). Araújo (1999) integrou dados geológicos por Combinação Linear Ponderada (CLP), Média 
Ponderada Ordenada (MPO) e análise Booleana. Araújo \& Macedo (2002) apresentam o método adaptado para dados geológicos e comparam os resultados das análise CLPe MPO, tendo concluído que os resultados dos dois tipos de análise são coerentes e demonstram as mesmas tendências de favorabilidade, embora os valores absolutos de classes não sejam os mesmos.

No caso da avaliação de favorabilidade, os fatores são constituídos pelos elementos principais relacionados aos parâmetros prospectivos, ou seja, são constituídos de elementos litológicos, estratigráficos, geoquímicos e estruturais. As regras de decisão são constituídas pelos critérios, sejam fatores e restrições, assim como pelos procedimentos de combinação dos critérios. As regras de decisão, desta maneira, dependem intrinsecamente do objetivo específico da análise. Para a avaliação de favorabilidade mineral, o objetivo específico é descrito como a definição de áreas mais prováveis à ocorrência de mineralizações.

A combinação linear ponderada (CLP) é uma variação da técnica de sobreposição de camadas ou índices somativos (index overlay). Esta técnica aplica índices ponderados aos níveis de informação antes de proceder a sobreposição, que em geral é feita a partir de uma operação algébrica de soma.

A Combinação Linear Ponderada (CLP) é aplicada de acordo com a seguinte equação (2), onde F é a favorabilidade em uma determinada célula, $\mathrm{p}_{\mathrm{ij}}$ é o peso da classe $\mathrm{j}$ de um mapa i e $\mathrm{x}_{\mathrm{i}}$ é o peso (classificação do critério) do mapa i:

$$
F=\sum p_{i j} \cdot x_{i}
$$

Araújo \& Macedo (2002) descrevem detalhadamente o método e sua aplicação em prospecção mineral.Os mapas de favorabilidade para os modelos Perau e Panelas (Figs. 8 e 9) foram comparados com as ocorrências minerais conhecidas na área a partir de uma tabulação cruzada (Tabela 6), para a análise por combinação linear ponderada, respectivamente, para os modelos Panelas e Perau. As ocorrências minerais foram utilizadas exclusivamente para comparar os resultados dos mapas de favorabilidade com os tipos e frequiências de ocorrências em relação às classes de favorabilidade mapeadas. As ocorrências minerais não foram utilizadas para auxiliar a ponderação dos fatores empregados na análise. Assim, pode-se avaliar a qualidade dos mapas resultantes e do método empregado.

A análise dos mapas e tabelas demonstra resultados razoáveis em termos de coerência entre a localização das ocorrências e as classes de favorabilidade mais altas. No caso do modelo Panelas o maior número de ocorrências permite maior confiança nos resultados apresentados, embora haja certa dispersão de ocorrências para classes de valor maior que 6. Esta dispersão está relacionada à confiabilidade dos mapas utilizados e aos modelos prospectivos utilizados. No caso do modelo Perau embora considere-se o resultado positivo, com apenas I ocorrência em classe de baixa favorabilidade, o nível de confiança é menor devido ao tamanho pequeno do conjunto de amostras de ocorrências minerais. O tratamento dos dados geológicos, geoquímicos e geofísicos é adequado e pode ser utilizado em áreas onde há poucas ocorrências minerais conhecidas.

CONCLUSÕES Os resultados obtidos mostram coerência entre os parâmetros prospectivos adotados e as ocorrências minerais, apesar do pequeno número de ocorrências para o modelo Perau. Os métodos de análise utilizados mostraram-se adequados às condições do Vale do Ribeira e aos dados disponíveis. A melhoria dos valores de dispersão apresentados no modelo Panelas assim como
Tabela 5 - Reclassificação dos fatores litológico, estratigráfico, geoquímico e estrutural - modelos Panelas e Perau.

\begin{tabular}{|c|c|c|}
\hline Classes & Função de pertinência & $\begin{array}{l}\text { Pontos de } \\
\text { controle:a-b }\end{array}$ \\
\hline Litologias favoráveis Perau & linear crescente & $0-10$ \\
\hline Litologias favoráveis Panclas & linear crescente & $0-10$ \\
\hline Unidades favoráveis Panelas/Pcrau & linear crescente & ()$-10$ \\
\hline $\begin{array}{l}\text { Distância dos contatos } \\
\text { carbonatos/xistos e filitos - } \\
\text { Panelas }\end{array}$ & sigmoidal decrescente & $100-300$ \\
\hline $\mathrm{Pb}$ & lincar crescente & $1-42.37$ \\
\hline $\mathrm{Zn}$ & linear crescente & $1-15$ \\
\hline $\mathrm{Cu}$ & linear crescente & $1-3,33$ \\
\hline $\begin{array}{l}\text { Distância dos cixos de dobras - } \\
\text { Panclas }\end{array}$ & sigmoidal decrescente & 50()$-750$ \\
\hline Distância das falhas - Panclas & sigmoidal decresecnte & $1.50-250$ \\
\hline Distância das falhas - Perau & sigmoidal decrescente & $5(0)-10(0)$ \\
\hline $\begin{array}{l}\text { Distância dos lineamentos } \\
\text { magnéticos - Panclas }\end{array}$ & sigmoidal decrescente & $150-250$ \\
\hline $\begin{array}{l}\text { Distância dos lineamentos } \\
\text { magnéticos - Perau }\end{array}$ & sigmoidal decrescente & $500-1000$ \\
\hline Eixos de fraturamento & linear crescente & $(0-10$ \\
\hline
\end{tabular}

Tabela 6 - Tabulação cruzada-modelos Panelas e Perau.

\begin{tabular}{l|llllllllll}
\hline $\begin{array}{l}\text { Classes da } \\
\text { imagem CLP }\end{array}$ & 1 & 2 & 3 & 4 & 5 & 6 & 7 & 8 & 9 & 10 \\
$\begin{array}{l}\text { Ocorrências } \\
\text { Perau (7) }\end{array}$ & 0 & 0 & 1 & 0 & 0 & 0 & 1 & 3 & 1 & 1 \\
$\begin{array}{l}\text { Ocortências } \\
\text { Panelas (82) }\end{array}$ & 0 & 0 & 0 & 0 & 0 & 1 & 57 & 5 & 17 & 2 \\
\hline
\end{tabular}

no modelo Perau (Tabela 6) está relacionada à utilização de fatores e classes baseados em dados não disponíveis atualmente. Os parâmetros prospectivos adotados consideraram 4 fatores bási$\cos$, que refletem os modelos utilizados, mas que são simplificadores de processos mineralizantes complexos. A adoção de novos fatores, como por exemplo padrões de fraturamento de detalhe, aliados a novos dados geofísicos e geoquímicos tornaria os resultados melhores.

No mapa de favorabilidade notou-se que as áreas mais favoráveis, em termos geológicos, nem sempre têm sobreposição de bacias anômalas de sedimentos de corrente. Isto é explicado pelo fato de os dados disponíveis vieram de levantamentos que visavam a prospecção mineral, e que, por isto, não eram realizados em áreas já sabidamente mineralizadas. Os altos teores das áreas mineralizadas conhecidas podiam encobrir as anomalias de outras áreas devido ao aumento dos teores médios do levantamento.

Os dados aeromagnéticos utilizados, devido à sua escala, não foram eficientes para detecção de elementos indicadores das mineralizações. Deste modo, é recomendada a utilização de dados aerogeofísicos, em escala de maior detalhe, visando a detecção de elementos indicadores de mineralização, como padrões de alteração hidrotermal a partir de dados gamaespectrométricos.

Em relação às hipóteses definidas para os modelos prospectivos adotados, verificou-se, no caso do modelo Perau, que as áreas mais favoráveis estão associadas aos elementos estratigráficos e litológicos, ou seja, essas áreas associam-se à presença de rochas metassedimentares, especialmente ao contato entre quartzitos e xistos da Formação Perau.

O contato entre xistos e rochas carbonáticas mostrou-se eficiente na definição de áreas favoráveis, para o tipo Panelas, 


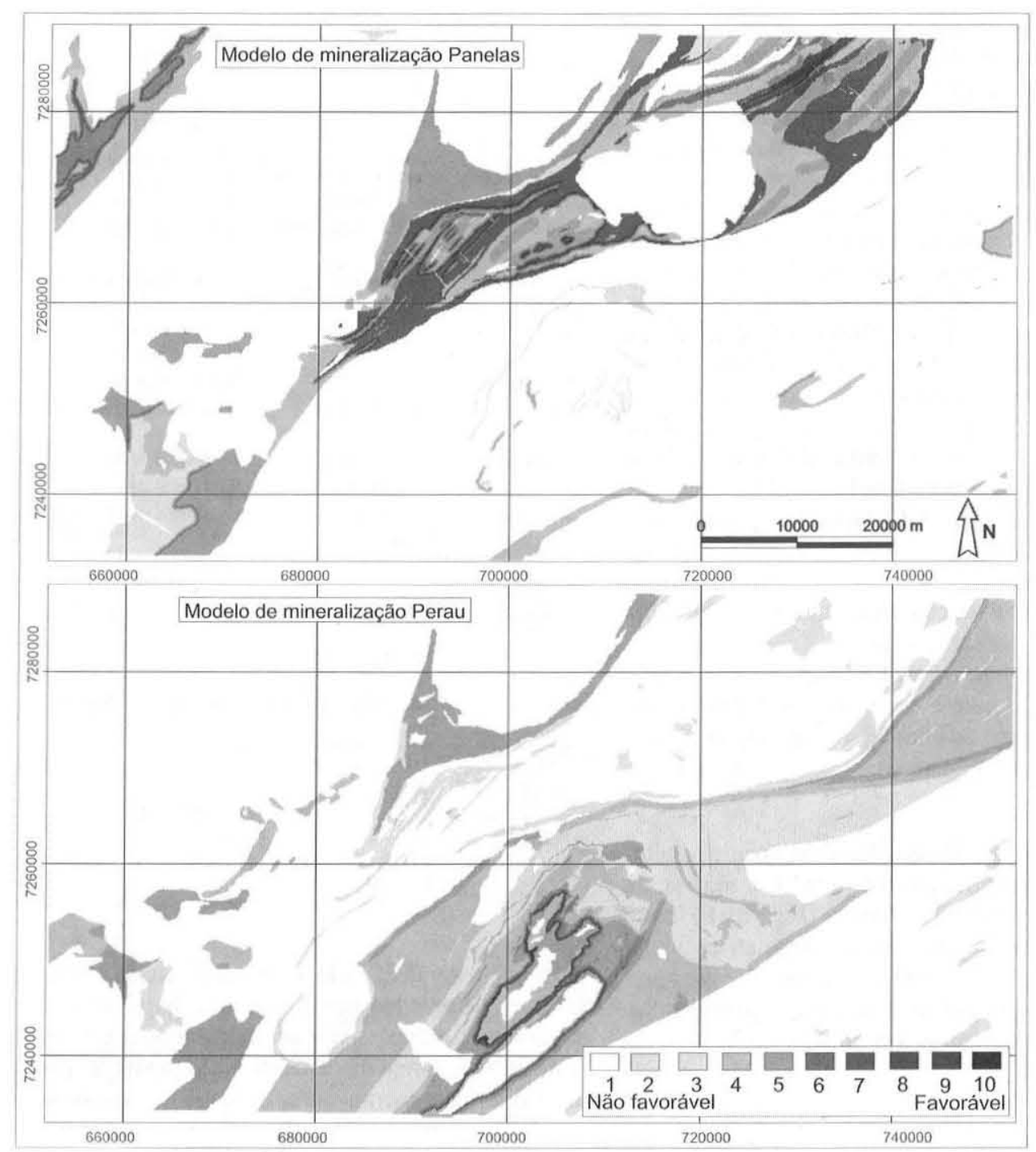

Figura 8-Mapas de Favorabilidade-modelos Perau e Panelas.

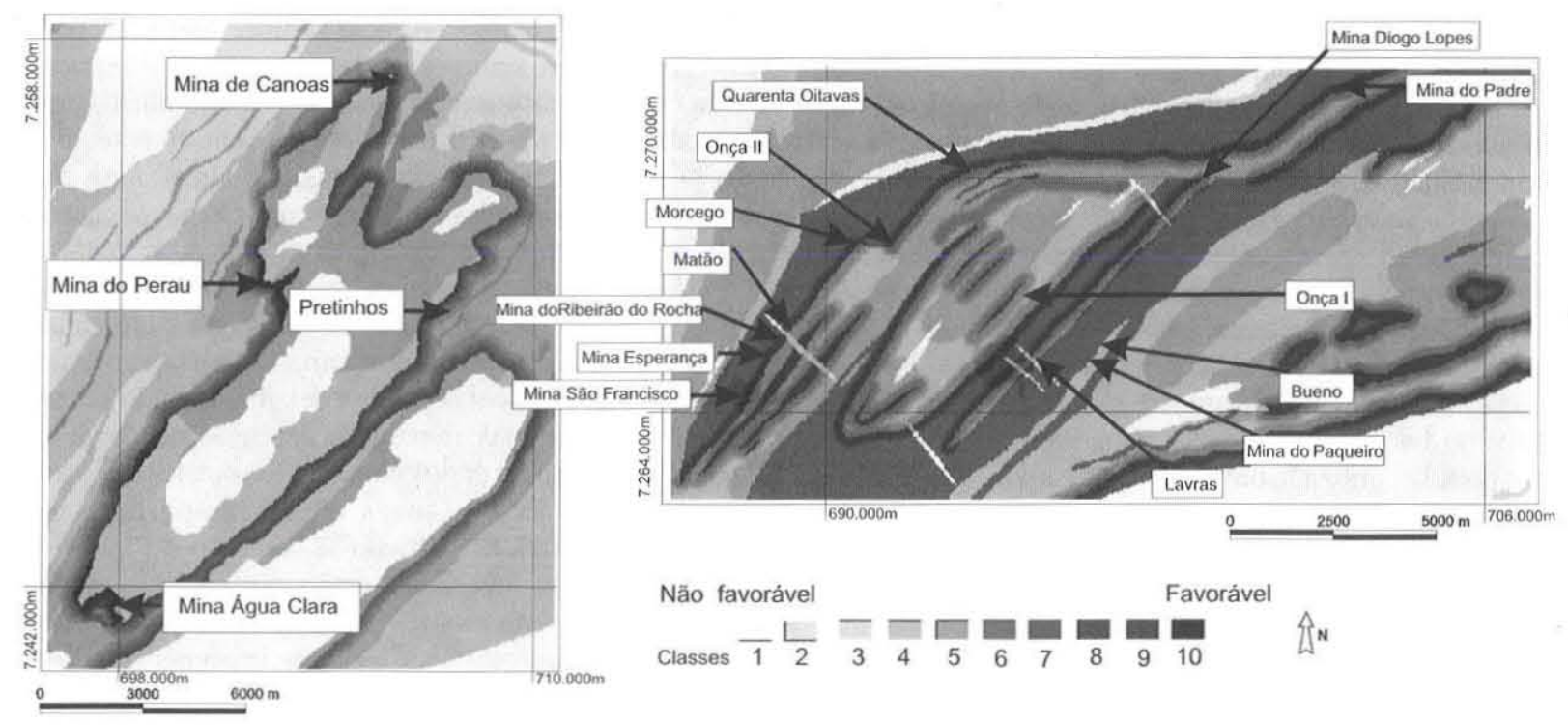

Figura 9- Détalles des mapas de' farorabilidade- modelos Perau e' Panelas. 
principalmente na região que abrange as minas do Rocha, Paqueiro e Quarenta Oitavas, o que é um reflexo dos controles lito-estruturais destas mineralizações.

Para a análise de favorabilidade, é recomendável o uso do geoprocessamento, pois este permite o uso de técnicas não aplicáveis manualmente e é fundamental na otimização dos trabalhos de organização e manutenção de grandes bancos de dados espaciais, gerados durante os trabalhos de prospecção mineral.

Devido aos resultados positivos apresentados (Tabela 6), recomenda-se a utilização dos métodos aplicados neste trabalho em áreas com condições semelhantes às estudadas. Em áreas desconhecidas ou com poucos dados geológicos, recomenda-se a utilização de levantamentos geoquímicos, além de sensoriamento remoto e aerogeofísica, organizados em um SIG, balizada por modelo prospectivo, seguindo os métodos apresentados, com as seguintes ressalvas: o resultado teria um nível de confiança mais baixo e não há possibilidade de testar os resultados sem pesquisa de campo detalhada.

No caso do modelo Panelas, a aplicação dos métodos utilizados em áreas menores (maior detalhe), acompanhada de levantamentos de campo de dados estruturais, permitiria melhor definição de alvos dentro das unidades litoestratigráficas carbonáticas, refinando-se a separação das áreas de alta favorabilidade. Do mesmo modo, recomenda-se a interpretação dos dados de zonas de fraturamento, em escala de maior detalhe (1:25.000), considerando-se as atitudes dos filões descritas na bibliografia.

Agradecimentos Ao Instituto de Geociências da Universidade de São Paulo pelo apoio logístico e à FAPESP pelo apoio financeiro. Os autores agradecem a todos os peritos anônimos consultados. Ao prof. Dr. Francisco José Ferreira da UFPR pela ajuda com o processamento de dados aerogeofísicos; ao prof. Dr. Ginaldo Adhemar da Cruz Campanha pelo auxílio com a compilação do mapa geológico. Ao prof. Dr. Elias Carneiro Daitx pela sugestões e críticas ao processamento de dados geoquímicos e compilação das ocorrências minerais. Aos revisores da RBG pelas sugestões ao manuscrito.

\section{Referências}

Araújo C.C. 1999. Aplicaşão de geoprocessamento na análise de favorabilidade para mineralizaçôes de chumbo, zinco e cobre nas follhas Cerro Azul e Apiaí. Vale do Ribeira (SP C PR). Dissertação de Mestrado, Instituto de Geociências, Universidade de São Paulo, 151 p.

Araújo C.C. \& Macedo A.B. 2002. Multicriteria geologic data analysis for mineral favorability mapping: application to a metal sulphide mineralized area, Ribeira Valley Metallogenic Province, Brazil. Natural Resources Research, 11:29-43.

Barbour A.P., Oliveira M.A.F. 1979. Pb, Zn, Cu e Ba do Distrito Perau - modelo sedimentar para sulfetos do Vale do Ribeira. Boletim IG USP. 10:97-120.

Barbour A.P., Oliveira M.A.D., Hypolito R. 1984. Geologia e Gênese do depósito estratiforme de $\mathrm{Pb}$ da Mina da Barrinha, Vale do Ribeira, PR. In: SBG, Congr. Bras. Geol., 23, Anais, p. 3641- 3657.

Barbour A.P. . Macedo A.B., Hypólito R. 1988. Correlação de elementos prata, chumbo, zinco e ferro com bário em algumas jazidas sulfetadas do Vale do Ribeira, Estado de São Paulo e Paraná. Boletim IG - USP, Série Científica, 19:1-21.

Barbour A.P., Brito Neves B.B., Medeiros R.A. 1990 Algumas implicações tectônicas na gênese das mineralizações sulfetadas do tipo Panelas no Vale do Ribeira, SP, PR. Rev: Bras.Geoc., 20:46-54.

Bonham-Carter G.F.. Agterberg F.P., Wright D.F. 1988. Integration of geological datasets for gold exploration in Nova Scotia. Photogram. Enginee. Remote Sensing, 54:1585-1592.

Bonham-Carter, G.F. 1994. Geographic Information Systems for Geoscientists. Pergamon, Ottawa, 397p.

Campanha G.A.C., Gimenez Filho A., Bistrichi C.A. 1996. Geologia da Folha Itararé. São Paulo, IPT, inédito, 31p. (Minuta de Relatório).

Chiodi Filho C., Alegri V., Batolla F., Ferreira J.C.G. 1982. Geologia e mineralizações da região que abrange as minas do Rocha, Paqueiro e Barrinha, Vale do Ribeira, PR e SP. In: SBG, Congr. Bras. Geol., 32, Ancis, 3:1037-1048.

CPRM-GEOFOTO. 1978. Projeto Serra do Mar Sul - Compilação de dados do levantamento aeromagnetométrico na região da Serra do Mar nos Estados de Santa Catarina e Paraná. Geofoto Lida, 48p.

\section{(Relatório Final).}

CPRM-ENCAL. 1979. Projeto Aerogeofísico São Paulo-Rio de Janeiro - Levantamento aeromagnetométrico e aerogamaespectrométrico, subáreas II e IV. Encal S/A, 48p. (Relatório Final).

CPRM-Microsiga. 1994. Sistema de Informações Geológicas do Brasil. Rio de Janeiro, CPRM (CD-ROM).

Daitx E.C., Moreschi J.B., Bettencourt J.S., Ruberti E., Bello R.M.S., Ferrer L.M. 1995. Gênese da jazida de Furnas: estabelecimento de um modelo genético para depósitos filonares de $\mathrm{Pb}(\mathrm{Zn}, \mathrm{Ag}) \mathrm{em}$ rochas carbonatadas do Vale do Ribeira, Estado de São Paulo. Relatório Final de Projeto de Pesquisa, 148 p. (Processo Fapesp 91/2842-8)

Daitx E.C. 1996. Origem e evolıção dos depósitos sulfetados tipo Perau ( $P b-Z n-A g)$, com base nas jazidas de Canoas e Perau (Vale do Ribei$r(a, P R)$. Tese de Doutoramento, Instituto de Geociências e Ciências Exatas, Universidade Estadual Paulista, Rio Claro, 453 p.

Damasceno E.C. 1967. Geologia da mina do Paqueiro. Tese de Doutoramento, Faculdade de Filosofia Ciências e Letras, Universidade de São Paulo, São Paulo, 69 p.

Eastman J.R. 1997. Idrisi for Windows, User's Guide, version 2.0. Clark Labs for Cartographic Technology and Geographic Analysis, Clark University, Worcester.

Figueiredo B.R. (coordenador). 1988. Implantação do índice de depósitos minerais do Estado de São Paulo - IDEM/SP. (Contrato UNICAMP/FUNCAMP - 479/87 e Pró-Minério/SCT - 1032/86). São Paulo, Unicamp, 51 p. (Relatório técnico final \& disquetes).

Finlow-Bates T. 1980. The chemical and physical control on the genesis of submarine exhalative orebodies and their implications for formulating exploration concepts - A review. Geolog. Jarbuch, Serie D, 40:131-168.

Fleischer R. 1976. A pesquisa de chumbo no Brasil. In: SBG, Congr: Bras. Geol., 29, Anais, 1:19-32.

Gunn P., Maidment D., Milligan P.R. 1997. Interpreting aeromagnetic data in areas of limited outcrop. AGSO J. Austral. Geol. Geoph. 17:175-185. 
Harris D.P. 1984. Mineral resources appraisal. Oxford, Clarendon Press, $445 p$.

Harris D.P. 1990. Mineral exploration decisions. New York, John Wiley \& Sons, 436p.

Hasui Y., Coppedê A.J., Caetano A.C., Sanchez L.H. 1992. Aspectos geológicos-estruturais na área da mina de Furnas (Município de Iporanga. SP) e o problema de fluxo de efluentes. In: Y. Hasui \& J.A. Mioto (eds). Geologia Estrutural Aplicada - Estudo de casos. IPT, São Paulo, pp.:399-410.

Large D.E. 1980. Geological parameters associated with sediment hosted, submarine exhalative $\mathrm{Pb}-\mathrm{Zn}$ deposits: an empirical model for mineral exploration. Geolog. Jahrbuch, Serie D, 40:59-129.

Licht O.A.B \& Tarvainen T. 1996. Multipurpose geochemical maps produced by integration of geochemical exploration datasets in the Paraní Shield. Brazil. J. Geochem. Explor., 56:167-182.

Lydon J.W. 1990. Volcanogenic massive sulphide deposits. In: R.G. Roberts \& P.A. Sheahan (eds) Ore Deposit Models. Toronto, Geological Association of Canada, Geoscience Canada, reprint series 3, $194 \mathrm{p}$.

Macedo A.B. 1986. Prospeç̧ão litogeocuámica na mina do Perau, Paraná. São Paulo. Tese de Doutoramento, Instituto de Geociências, Universidade de São Paulo, São Paulo, 162 p.

Macedo A. B. 1996. Reflexões sobre tratamentos de dados geoquímicos. Tese de Livre Docência, Instituto de Geociências, Universidade de São Paulo. São Paulo, 151 p.

MMAJ-JICA. 1981. Report on geological survey of Anta Gorda - Brazil - phase 1. Convênio DNPM/JICA/MMAJ, Tokyo, 79 p.

MMAJ-JICA. 1982. Report on geological survey of Anta Gorda - Brazil - phase 2. Convênio DNPM/JICA/MMAJ, Tokyo, 119 p.

MMAJ-JICA. 1983. Report on geological survey of Anta Gorda - Brazil - phase 3. Convênio DNPM/JICA/MMAJ, Tokyo, 111 p.

Morgental A., Batolla Júnior F., Pinto G.G., Paiva I.P., Drumond J.B.V. 1975. Projeto Sudelpa: fichas de ocorrências. São Paulo: Sudelpa/ CPRM, 1975, 18v.
Morgental A., Silva A.A.G.P. da, Borin Júnior T., Alegri V., Oliveira P. E.P. 1978. Projeto geoquímica no Vale do Ribeira, escala 1:100.000. DNPM/CPRM, São Paulo, 8 v. (Relatório final).

Odan Y., Fleischer R., Espourteille F. 1978. Geologia da mina de chumbo de Panelas-Adrianópolis - PR. In: SBG, Congr. Bras. Geol., 30. Anciis, 4:1545-1552.

Rodrigues, M. 1990. Geoprocessamento. In: EPUSP, Simpósio Brasileiro de Geoprocessamento, 1. São Paulo, p. 1-27.

Silva C.R., Takahashi A.T., Chiodi Filho C., Batolla JR. F. 1982, Geologia e mineralizações na região do Perau - Água Clara, Vale do Ribeira, PR. In: SBG, Congr. Bras. Geol., 32, Anciis, 3: 1024-1036.

Silva R. B., Maeyama O., Perosa P. T., Almeida E.B., Saragiotto J.A.R. 1982. Considerações sobre as mineralizações de chumbo, zinco e prata do Grupo Açungui no Estado de São Paulo. In: SBG, Congr. Bras. Geol., 32, Anais. 3:972 - 986.

Sinclair A. J. 1974. Selection of threshold values in geochemical data using probability graphs. J. Geoch. Explor., 3:129-149.

Souza I.M. \& Campanha G.A.C. 1977. Chumbo e cobre no Vale do Ribeira, mina Barra do Perau, município de Adrianópolis, estado do Paraná. Mineração e Metalurgia, 40:4 -7.

Stanley C.R. 1987. An interactive computer program to fit mixtures of normal (or log-normal) distributions with maximum likelihood optimization procedures - version 1.0. Association of Exploration Geochemists Canada, Special Volume 14, 40 p.

Tassinari C.G.C., Barbour A.P., Daitx E.C., Sato K. 1990. Aplicação dos isótopos de $\mathrm{Pb}$ e $\mathrm{Sr}$ ba determinação da natureza das fontes das mineralizações de chumbo do Vale do Ribeira - SP e PR. In: SBG, Congr. Bras. Geol., 36, Anais. 3:1254- 1266.

Williams X.K. 1967. Statistics in the Interpretation of Geochemical Data. New Zealand J. Geol. Geoph., 10:771-97.

Manuscrito A-1361

Recebido em 27 de seetembro de 2002

Revisão dos autores em 15 de maio de 2004

Revisão aceita em 15 de junho de 2004 